\title{
BLICKDIAGNOSE-QUIZ-AUFLÖSUNG
}

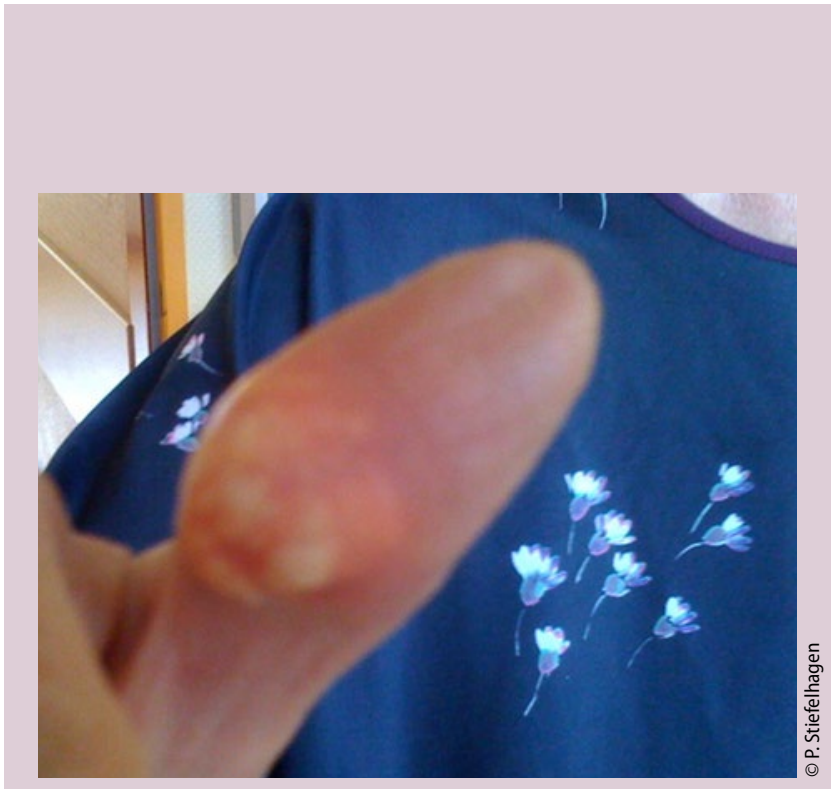

Weißlich-gelbliche Verhärtungen am Daumen.
Handbefund I

\section{Der Knubbel ist das, wonach er aussieht}

Auflösung von Seite 7.

Richtige Antwort:

A) Tophi bei chronischer Gicht

_ Bei dem Patienten ist seit einigen Jahren auch eine Gicht bekannt, die mehrmals zu einer Arthritis urica im Großzehengrundgelenk geführt hat. Zusätzlich haben sich Gichttophi am Daumen und an den Ohrmuscheln entwickelt. Dabei handelt es sich um kugelige, schmerzfreie, weißlich-gelbliche Uratablagerungen in Weichteilen und Knorpelgewebe, die sich langsam, über Jahre hinweg entwickeln. Sie sind ein sicherer Hinweis auf eine länger bestehende Gicht, die dann meist auch schon zu einer Gichtniere geführt hat. Typischerweise sind Ohrmuscheln, Füße, Knie, Ellbogen, Handgelenke und Finger betroffen.

Eine operative Entfernung sollte bei Gichtknoten nur dann in Erwägung gezogen werden, wenn sie die Gelenkfunktion beeinträchtigen. Im Vordergrund steht die Therapie der Hyperurikämie.

$\rightarrow$ Dr. med. Peter Stiefelhagen

DRK-Krankenhaus, Alte Frankfurter Str. 12, D-57627 Hachenburg

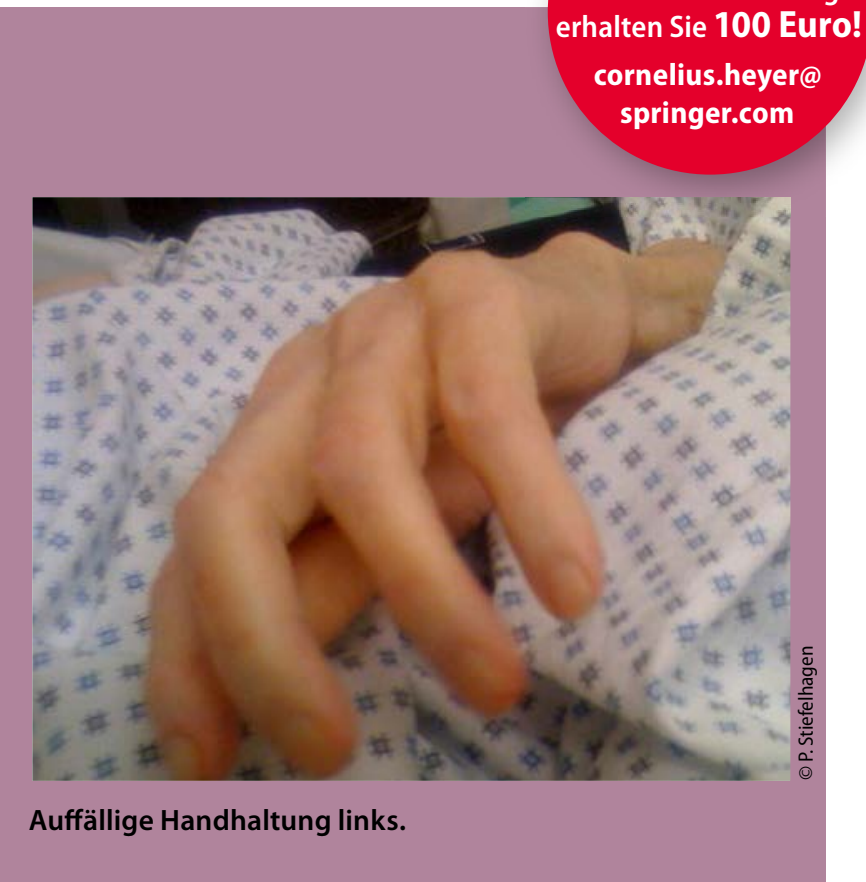

Handbefund II

\section{Das ist eine typische Pfötchenstellung}

Auflösung von Seite 7.

Richtige Antwort:

C) Pfötchenstellung bei hypokalzämischer Tetanie

Es handelt sich um eine typische Pfötchenstellung bei Tetanie. Ursache ist eine Hypokalzämie bei iatrogenem Hypoparathyreoidismus. Der Mangel an Kalziumionen führt zu einer neuromuskulären Übererregbarkeit. Typischerweise kommt es zu tetanischen Anfällen mit ängstlicher Unruhe, Taubheitsgefühl, Missempfindungen und Muskelkrämpfen, die an den Händen zur Pfötchenstellung führen.

Bei der Patientin war vor vielen Jahren eine Strumektomie durchgeführt worden. Dabei dürften auch die Nebenschilddrüsen entfernt worden sein. Deshalb wurde in der Folgezeit eine Parathormon-Substitution eingeleitet, die - soweit eruierbar in den letzten Monaten jedoch versehentlich weggelassen worden war.

Eine Pfötchenstellung der Hände zeigt sich oft auch bei der Hyperventilation. Dabei kommt es durch die Hyperventilation zu einer Alkalose mit der Folge, dass vermehrt Kalzium an Proteine gebunden wird. Das Gesamtkalzium bleibt also normal, nur das freie verfügbare Kalzium ist vermindert. 